\title{
Caracterização de formas botânicas diversas do Banco Ativo de Germoplasma de cafeeiros do Estado de Minas Gerais, Brasil
}

\author{
João Marcos Rodrigues Andrade Lara ('); Juliana Costa de Rezende (2*); Gladyston Rodrigues \\ Carvalho ( $\left.{ }^{2}\right)$; Antonio Alves Pereira $\left({ }^{3}\right)$; João Paulo Felicori Carvalho ( $\left.{ }^{1}\right)$; Oliveiro Guerreiro Filho $\left({ }^{4}\right)$ \\ (1) Universidade Federal de Lavras (UFLA), Caixa Postal 3032, 37200-000 Lavras (MG), Brasil. \\ (2) Empresa de Pesquisa Agropecuária de Minas Gerais (EPAMIG), Campus da UFLA, 37200-000 Lavras (MG), Brasil. \\ (3) EPAMIG, Campus da UFV, 36571-000 Viçosa (MG), Brasil. \\ (4) Instituto Agronômico (IAC), Centro de Café, Avenida Barão de Itapura, 1481 13020-902 Campinas (SP), Brasil. \\ (*) Autora correspondente: julianacr@epamig.ufla.br
}

Recebido: 25/jun./2014; Aceito: 5/set./2014

\begin{abstract}
Resumo
O objetivo do trabalho foi caracterizar 21 acessos de formas botânicas diversas de cafeeiro existentes no Banco Ativo de Germoplasma do Estado de Minas Gerais, com o intuito de identificar genótipos com potencial de uso em programas de melhoramento genético. No ensaio de campo, cada acesso é representado por 20 plantas, distribuídas em delineamento em blocos ao acaso com duas repetições. Os cafeeiros foram avaliados aos 30 meses após o plantio, de acordo com a produtividade, o vigor vegetativo e com os principais descritores mínimos para a proteção de cultivares de café no Brasil. Os resultados obtidos revelam importante variabilidade genética entre os acessos, evidenciando a possibilidade de seu uso em programas de melhoramento. O acesso Pacamara apresentou produtividade superior no primeiro ano, enquanto que, no segundo ano, destacaram-se os acessos Catuaí Erecta e Semperflorens. Os descritores mínimos utilizados para a proteção de cultivares de café revelaram-se uma ferramenta eficiente para a caracterização e diferenciação do germoplasma estudado.
\end{abstract}

Palavras-chave: Coffea arabica, melhoramento do cafeeiro, variabilidade, recursos genéticos.

\section{Characterization of various forms of botanical at the Active Bank Germplasm for coffee the Minas Gerais State, Brazil}

\begin{abstract}
The objective of this study was to characterize 21 accessions of various botanical forms of existing coffee in the Active Germplasm Bank of the State of Minas Gerais, in order to identify genotypes with potential for use in breeding programs. In the field trial, each access is represented by 20 plants, in randomized complete block design with two replications. Coffee plants were evaluated at 30 months after planting, according to productivity, vegetative vigor and the main standard descriptors for the protection of plant varieties of coffee in Brazil. The results show an important genetic variability among accessions showing the possibility of their use in breeding programs. The Pacamara access had higher productivity in the first year, while in the second year, stood accesses Catuaí Erecta and Semperflorens. The standard descriptors used for the protection of plant varieties of coffee proved to be an efficient tool for the characterization and differentiation of germplasm studied.
\end{abstract}

Key words: Coffea arabica, coffee breeding, variability, genetic resources.

\section{INTRODUÇÃO}

Os bancos de germoplasma representam um acervo de genes e um reservatório de variabilidade genética natural, potencial e indispensável para os programas de melhoramento das espécies cultivadas não renováveis (Costa et al., 2011), gerando a necessidade estratégica de conservá-los. Coimbra et al. (2012) ressaltam que o valor da variabilidade genética está em sua utilização e que somente com a caracterização dos acessos disponíveis se pode conhecer suficientemente a diversidade genética preservada (Campos et al., 2010). Essa caracterização dos acessos que compóem as coleçôes é de fundamental importância para o conhecimento das potencialidades delas, identificando-se assim a variabilidade entre e dentre as populaçôes (Lima et al., 2012).

A coleção de acessos de Coffea implantada na Fazenda Experimental de Patrocínio da Empresa de Pesquisa 
Agropecuária de Minas Gerais (Epamig), é composta por aproximadamente 1.500 acessos, dentre eles diversos mutantes que representam formas silvestres espontâneas e subespontâneas de C. arabica. Algumas dessas mutaçóes de natureza gênica têm sido úteis para o desenvolvimento de cultivares, mas em sua grande maioria elas são deletérias e recessivas, tendo sido encontradas em viveiros e em lavouras, afetando quase todos os caracteres das plantas, desde o porte e tipo de ramificação até características de folhas, flores, frutos e sementes (Carvalho et al., 1991).

Entre os acessos estudados, alguns são caracterizados por mutaçôes que alteram a morfologia dos ramos ortotrópicos (Polyorthotropica), plagiotrópicos (Erecta), ou de ambos os ramos (São Bernardo). O mutante Purpuracens apresenta folhas e frutos de coloração púrpura, enquanto Volutifolia possui forma e número de folhas afetadas. Algumas mutações têm implicação no florescimento das plantas (Semperflorens), em características dos frutos (Goiaba), na cor (Cera) ou forma das sementes (Laurina). Outro grupo de mutantes, como Maragogipe, Mokka, Polysperma e Angustifolia, tem afetado o desenvolvimento de vários órgãos das plantas.

Dessa forma, o objetivo do trabalho foi caracterizar os acessos de formas botânicas diversas existentes no Banco Ativo de Germoplasma de Café do Estado de Minas Gerais (BAG), com o intuito de identificar genótipos com potencial de uso em programas de melhoramento genético.

\section{MATERIAL E METODOS}

O BAG está instalado na Fazenda Experimental de Patrocínio da Epamig, localizada na região do Alto Paranaíba, situada a $18^{\circ} 59^{\prime} 26^{\prime \prime}$ de latitude sul, 48 $58^{\prime} 95^{\prime \prime}$ de longitude oeste e altitude local de aproximadamente mil metros. O solo é do tipo Latossolo Vermelho-amarelo distrófico e a topografia é plana, com ligeira inclinação. $\mathrm{O}$ clima do município de Patrocínio é classificado como Clima Mesotérmico Subtropical Temperado, com chuvas de verão, inverno seco e veráo quente (Wca), segundo Koppen.

Características morfológicas foram avaliadas em 21 acessos de formas botânicas diversas de C. arabica L. Esses acessos apresentam potencial de uso imediato no Programa de Melhoramento Genético do cafeeiro de Minas Gerais. Cada acesso foi composto de 20 plantas, divididas em duas repetiçóes. Ao contrário da maioria dos bancos de germoplasma, o BAG dispóe de repetição, permitindo a quantificação da influência do ambiente sobre as constituiçóes genéticas. O delineamento experimental utilizado foi o de blocos ao acaso com duas repetições, sendo as parcelas experimentais compostas de 10 plantas. $\mathrm{O}$ espaçamento utilizado foi 3,5 $\mathrm{m} \times 1,0 \mathrm{~m}$ nas entrelinhas e entre plantas, respectivamente.

O manejo e a condução do BAG foram realizados de acordo com as recomendaçôes técnicas para a cultura do cafeeiro. O manejo fitossanitário foi feito preventivamente ou curativamente, por meio de produtos químicos, acompanhando a sazonalidade da ocorrência de pragas e doenças.

Aos 30 meses após o plantio, os acessos foram avaliados de acordo com os principais descritores mínimos utilizados para a proteção de cultivares de café estabelecidos pelo Serviço Nacional de Proteção de Cultivares (SNPC) (Tabela 1). Também foram avaliadas neste trabalho a produtividade $\left(\right.$ sacas.h $\left.\mathrm{a}^{-1}\right)$ dos acessos no primeiro ano e no segundo ano, de acordo com a metodologia descrita por Botelho et al. (2010a) e o vigor vegetativo.

As avaliaçóes de produtividade foram realizadas entre os meses de maio a julho de cada ano, medidas em sacas.ha ${ }^{-1}$. O diâmetro da copa foi medido no terço médio da copa e a altura da planta, medida a partir do colo até o meristema apical, em metros. A avaliaçáo do vigor vegetativo foi realizada conforme escala de pontos sugerida por Carvalho et al. (1979), sendo 1 ponto atribuído às plantas com vigor vegetativo muito reduzido e acentuado sintoma de depauperamento e 10 pontos, às plantas com excelente vigor, mais enfolhadas $\mathrm{e}$ com acentuado crescimento vegetativo dos ramos produtivos. A massa de 100 sementes foi avaliada em gramas, por meio de uma balança de precisão.

Os dados obtidos nas avaliaçóes das variáveis produtividade do primeiro ano (Prod01) e do segundo ano (Prod02), altura das plantas (Alt), diâmetro de copa (DC), vigor vegetativo (VV) e massa de 100 sementes (MS) foram submetidos à análise de variância no aplicativo computacional SISVAR (Ferreira, 2008), sendo as médias dos tratamentos comparadas pelo teste de Scott e Knott (1974), a 5\% de probabilidade. As características qualitativas foram avaliadas por meio da atribuiçáo de pontos utilizados na tabela de descritores mínimos para a proteção de cafeeiros (Tabela 1), não sendo analisadas estatisticamente.

\section{RESULTADOS E DISCUSSÃO}

Exceção feita à MS, a análise de variância realizada revelou efeito significativo $(\mathrm{p}<0,05)$ para as demais cinco características quantitativas avaliadas (Tabela 2). $\mathrm{O}$ coeficiente de variaçấo (CV) experimental variou de 9,82\% (Alt) a 44,98\% (Prod01), indicando menor influência do ambiente sobre a primeira característica e maior sobre a segunda. CV elevados são bastante comuns em ensaios de progênies de cafeeiros de natureza diversa, mesmo em linhas isogênicas, como observado por Mônaco e Carvalho (1964). De acordo com Ferrão et al. (2008), a ocorrência de CV elevado para dados de produçáo de café de roça pode ser devida, principalmente, ao longo ciclo da cultura, a respostas diferenciadas dos materiais a altas temperaturas, secas, incidência de doenças e pragas e vento. 
Tabela 1. Características avaliadas, respectivas classes e códigos segundo lista oficial de descritores mínimos para a cultura do cafeeiro

\begin{tabular}{|c|c|}
\hline Característica & Classes \\
\hline \multicolumn{2}{|r|}{ Planta } \\
\hline Formato & Cilíndrico (1); cônico (2); cilíndrico-cônico (3); cônico invertido (4) \\
\hline Altura da planta & Muito baixa (1); baixa (3); média (5); alta (7); muito alta (9) \\
\hline Diâmetro da copa & Muito pequeno (1); pequeno (3); médio (5); grande (7); muito grande (9) \\
\hline Comprimento do internódio & Curto (3); médio (5); longo (7) \\
\hline Ramificação plagiotrópica: tipo & Ereta (1); semiereta (2); horizontal (3); semipendente (4) \\
\hline Ramificação plagiotrópica: intensidade & Baixa (3); média (5); alta (7) \\
\hline Ramo ortotrópico: flexibilidade & Baixa (3); média (5); alta (7) \\
\hline \multicolumn{2}{|r|}{ Folha } \\
\hline Comprimento & Curto (3); médio (5); longo (7) \\
\hline Largura & Estreita (3); média (5); larga (7) \\
\hline Forma & Elíptica (1); ovalada (2); lanceolada (3) \\
\hline Cor da folha jovem & Verde (1); bronze (2); verde e bronze (3); púrpura (4) \\
\hline Cor da folha adulta & Verde-clara (1); verde-escura (2); púrpura (3) \\
\hline Ondulação das bordas & Ausente (1); presente (9) \\
\hline Intensidade de ondulação & Fraca (3); média (5); forte (7) \\
\hline Domácias & Ausentes (1); parcialmente desenvolvidas (2); bem desenvolvidas (3) \\
\hline Pubescência das domácias & Ausente (1); presente (9) \\
\hline \multicolumn{2}{|r|}{ Flor } \\
\hline Inflorescências/axila & Baixa (3); média (5); alta (7) \\
\hline Flores/inflorescência & Baixa (3); média (5); alta (7) \\
\hline \multicolumn{2}{|r|}{ Fruto } \\
\hline Tamanho & Muito pequeno (1); pequeno (3); médio (5); grande (7); muito grande (9) \\
\hline Formato & Redondo (1); elíptico (2); oblongo (3) \\
\hline Cor & Amarela (1); vermelho alaranjada (2); vermelha média (3); vermelha escura (4) \\
\hline Grau de aderência ao ramo & Baixo (3); médio (5); alto (7) \\
\hline Sépala & Ausente (1); presente (2) \\
\hline \multicolumn{2}{|r|}{ Semente } \\
\hline Comprimento & Curto (3); médio (5); longo (7) \\
\hline Largura & Estreita (3); média (5); larga (7) \\
\hline Espessura & Fina (3); média (5); grossa (7) \\
\hline Cor do endosperma & Amarela (1); verde (2) \\
\hline Tonalidade da película prateada & Clara (1); escura (2) \\
\hline Aderência da película prateada & Fraca (3); média (5); forte (7) \\
\hline Peso de 100 sementes & Baixo (3); médio (5); alto (7) \\
\hline
\end{tabular}

Tabela 2. Resumo da análise de variância para os dados de produtividade do primeiro ano (Prod01) e do segundo ano (Prod02), altura das plantas (Alt), diâmetro de copa (DC), vigor vegetativo (VV) e massa de 100 sementes (MS) avaliadas nos mutantes

\begin{tabular}{|c|c|c|c|c|c|c|c|}
\hline \multirow{2}{*}{ FV } & \multirow{2}{*}{ GL } & \multicolumn{5}{|c|}{ Quadrado médio } & \multirow[b]{2}{*}{ MS } \\
\hline & & Prod01 & Prod02 & Alt & DC & VV & \\
\hline Mutantes & 21 & $117,90^{*}$ & $140,71^{*}$ & $0,27^{*}$ & $0,10^{*}$ & $3,36^{*}$ & 2,86 \\
\hline Repetição & 1 & 42,36 & 14,18 & 0,24 & 0,02 & 0,81 & 0,03 \\
\hline Erro & 21 & 15,77 & 19,50 & 0,03 & 0,02 & 1,05 & 5,05 \\
\hline CV (\%) & & 44,98 & 41,63 & 9,82 & 11,66 & 17,83 & 18,25 \\
\hline Média & & 8,83 & 10,61 & 1,69 & 1,34 & 5,75 & 12,31 \\
\hline
\end{tabular}

*Significativo a $5 \%$ de probabilidade.

As médias das seis variáveis quantitativas analisadas encontram-se na tabela 3. Nota-se que o acesso Pacamara223 destacou-se dos demais tratamentos na primeira colheita por apresentar média de Prod01 igual a 30,36 sacas.ha ${ }^{-1}$. Pacamara é uma cultivar originária de cruzamento entre as cultivares Pacas e Maragogipe, ambas de frutos vermelhos. A produção da Maragogipe caracteriza-se por ser baixa, porém, possui boa qualidade de bebida (Guedes et al., 2013). Nossos resultados corroboram dados obtidos por Mônaco (1960). O autor publicou resultados sobre a seleção de linhagens de café Maragogipe que evidenciaram a baixa produtividade do germoplasma. Em suas pesquisas, cafeeiros heterozigotos para o alelo maragogipe (Mgmg) revelaramse pouco mais produtivos do que aqueles homozigotos 
Tabela 3. Média dos tratamentos para as características produtividade do primeiro ano (Prod01) e produtividade do segundo ano (Prod02), em sacas.ha ${ }^{-1}$ altura das plantas (Alt), em metros, diâmetro de copa (DC), em metros, vigor vegetativo (VV), em notas, e massa de 100 sementes (MS), em gramas, avaliadas nos mutantes

\begin{tabular}{lcccccc}
\multicolumn{1}{c}{ Acessos } & Prod01 & Prod02 & Alt & DC & VV & MS \\
\hline Pacamara 223 & $30,36 \mathrm{a}$ & $9,23 \mathrm{c}$ & $1,33 \mathrm{~b}$ & $1,43 \mathrm{a}$ & $7,25 \mathrm{a}$ & $11,65 \mathrm{a}$ \\
\hline Polyorthotopica & $19,05 \mathrm{~b}$ & $6,85 \mathrm{c}$ & $2,08 \mathrm{a}$ & $1,54 \mathrm{a}$ & $5,55 \mathrm{a}$ & $11,40 \mathrm{a}$ \\
\hline Catuaí Erecta & $19,05 \mathrm{~b}$ & $27,98 \mathrm{a}$ & $1,58 \mathrm{~b}$ & $1,47 \mathrm{a}$ & $7,25 \mathrm{a}$ & $12,00 \mathrm{a}$ \\
\hline Goiaba 242 & $15,18 \mathrm{~b}$ & $21,43 \mathrm{~b}$ & $2,41 \mathrm{a}$ & $1,63 \mathrm{a}$ & $6,75 \mathrm{a}$ & $16,10 \mathrm{a}$ \\
\hline Glaucia & $14,29 \mathrm{~b}$ & $5,36 \mathrm{c}$ & $1,68 \mathrm{~b}$ & $1,39 \mathrm{a}$ & $7,19 \mathrm{a}$ & $12,50 \mathrm{a}$ \\
\hline Pacamara 224 & $14,29 \mathrm{~b}$ & $20,83 \mathrm{~b}$ & $1,39 \mathrm{~b}$ & $1,37 \mathrm{a}$ & $7,75 \mathrm{a}$ & $11,60 \mathrm{a}$ \\
\hline Laurina 228 & $10,71 \mathrm{c}$ & $14,88 \mathrm{~b}$ & $1,33 \mathrm{~b}$ & $1,21 \mathrm{a}$ & $5,60 \mathrm{a}$ & $12,90 \mathrm{a}$ \\
Polysperma 227 & $10,12 \mathrm{c}$ & $7,74 \mathrm{c}$ & $1,41 \mathrm{~b}$ & $1,30 \mathrm{a}$ & $6,41 \mathrm{a}$ & $12,00 \mathrm{a}$ \\
\hline Polysperma 225 & $9,82 \mathrm{c}$ & $17,86 \mathrm{~b}$ & $1,39 \mathrm{~b}$ & $1,43 \mathrm{a}$ & $6,07 \mathrm{a}$ & $12,70 \mathrm{a}$ \\
Goiaba 243 & $7,74 \mathrm{c}$ & $17,27 \mathrm{~b}$ & $2,17 \mathrm{a}$ & $1,52 \mathrm{a}$ & $6,73 \mathrm{a}$ & $12,85 \mathrm{a}$ \\
\hline Cera & $7,15 \mathrm{c}$ & $7,44 \mathrm{c}$ & $2,03 \mathrm{a}$ & $1,42 \mathrm{a}$ & $6,13 \mathrm{a}$ & $12,65 \mathrm{a}$ \\
Semperflorens 1193 & $6,25 \mathrm{c}$ & $6,55 \mathrm{c}$ & $1,62 \mathrm{~b}$ & $1,35 \mathrm{a}$ & $4,15 \mathrm{~b}$ & $11,65 \mathrm{a}$ \\
\hline Semperflorens 238 & $3,58 \mathrm{c}$ & $29,46 \mathrm{a}$ & $1,96 \mathrm{a}$ & $1,35 \mathrm{a}$ & $5,30 \mathrm{~b}$ & $11,15 \mathrm{a}$ \\
Volutifolia & $3,28 \mathrm{c}$ & $2,39 \mathrm{c}$ & $1,91 \mathrm{a}$ & $1,37 \mathrm{a}$ & $6,36 \mathrm{a}$ & $12,50 \mathrm{a}$ \\
\hline Angustifolia & $3,28 \mathrm{c}$ & $5,66 \mathrm{c}$ & $1,07 \mathrm{~b}$ & $0,94 \mathrm{~b}$ & $4,82 \mathrm{~b}$ & $10,45 \mathrm{a}$ \\
\hline Laurina 229 & $2,68 \mathrm{c}$ & $9,23 \mathrm{c}$ & $1,57 \mathrm{~b}$ & $1,42 \mathrm{a}$ & $5,80 \mathrm{a}$ & $11,35 \mathrm{a}$ \\
\hline São Bernardo & $2,68 \mathrm{c}$ & $3,28 \mathrm{c}$ & $1,41 \mathrm{~b}$ & $1,06 \mathrm{~b}$ & $4,39 \mathrm{~b}$ & $11,85 \mathrm{a}$ \\
\hline Maragogipe & $2,38 \mathrm{c}$ & $2,68 \mathrm{c}$ & $2,12 \mathrm{a}$ & $1,51 \mathrm{a}$ & $4,03 \mathrm{~b}$ & $11,90 \mathrm{a}$ \\
\hline Purpuracens & $0,15 \mathrm{c}$ & $2,98 \mathrm{c}$ & $1,80 \mathrm{a}$ & $1,30 \mathrm{a}$ & $7,12 \mathrm{a}$ & $14,15 \mathrm{a}$ \\
\hline Angustifolia & $0,00 \mathrm{c}$ & $7,15 \mathrm{c}$ & $2,08 \mathrm{a}$ & $1,58 \mathrm{a}$ & $2,98 \mathrm{~b}$ & $11,35 \mathrm{a}$ \\
\hline Mokka & $0,00 \mathrm{c}$ & $0,00 \mathrm{c}$ & $1,08 \mathrm{~b}$ & $0,63 \mathrm{c}$ & $4,17 \mathrm{~b}$ & $12,50 \mathrm{a}$ \\
\hline
\end{tabular}

Médias seguidas de mesma letra não diferem entre si a 5\% de probabilidade pelo teste de Scott e Knott (1974).

$(M g M g)$. Segundo Carvalho (1939), as principais causas da baixa produtividade da cultivar devem-se às reduzidas ramificaçóes primária e secundária das plantas e a um menor número de flores por axila. Entretanto, a recombinação de Maragogipe com Pacas, uma cultivar salvadorenha de boa produção derivada do Bourbon, desperta grande interesse para possíveis cruzamentos futuros.

No segundo ano, os acessos Catuaí Erecta e Semperflorens 238 apresentaram produçôes superiores, com 27,98 e 29,46 sacas.ha ${ }^{-1}$, respectivamente. O potencial produtivo do Catuaí foi relatado por outros autores. Botelho et al. (2010b), avaliando a adaptabilidade e estabilidade fenotípica de cultivares de café arábica em três regiōes distintas de Minas Gerais, observaram desempenho superior em produtividade para Catuaí Vermelho IAC 15, IAC 72, IAC 99 e Catuaí Amarelo IAC 62, IAC 30. Martins et al. (1992) analisaram progênies de Catuaí, Caturra e Mundo Novo, em Pindorama, no estado de Sáo Paulo, e observaram que o grupo de progênies de Catuaí Amarelo foi 32,8\% mais produtivo que o de Mundo Novo. De maneira geral, plantas que apresentam o gene $E r$ possuem produtividade insatisfatória (Carvalho et al., 1991), ao contrário do mutante relatado no presente trabalho. Dessa forma, a utilização desse Catuaí com os ramos laterais erectos em cruzamentos com outras cultivares produtivas poderia gerar novas cultivares, visando o maior adensamento da lavoura.

Em relação à altura de plantas, as médias dos diferentes tratamentos se dividiram em dois grupos (Tabela 3). No grupo de menor altura ficaram São Bernardo, Pacamara, Polysperma,
Laurina, Catuaí Erecta, Mokka, Angustifolia, Glaucia e Semperflorens 1193. Análises genéticas de genes que reduzem o comprimento dos internódios, realizadas por pesquisadores do IAC, revelaram-se bastante complexas e sugerem a existência de três a cinco locos gênicos (Carvalho et al., 1991) envolvidos na expressão do caráter. Sabe-se que o mutante São Bernardo apresenta os alelos dominantes $S b S b$, responsáveis pelo seu porte reduzido. O Polysperma 225 e o Catuaí Erecta são portadores do mesmo fator genético que reduz o porte das plantas (CtCt e Ctct, respectivamente), resultantes de seus parentais Villa Sarchi e Caturra, respectivamente.

Em relação ao diâmetro de copa, os acessos avaliados foram divididos em três grupos, sendo que a maioria deles permaneceu no grupo de maior diâmetro. O grupo intermediário foi composto pelo Angustifolia e pelo São Bernardo. O acesso Mokka representa isoladamente um terceiro grupo, com menor diâmetro de copa. Esses resultados já eram esperados, já que alelos dominantes $S b S b$ conferem ao São Bernardo, além seu porte reduzido, internódios muito curtos. Da mesma forma, a variedade Mokka caracteriza-se pelo pequeno porte, copa cônica, ramos plagiotrópicos e internódios curtos.

Os 14 acessos mais vigorosos também apresentaram maior diâmetro de copa, sendo essas duas características correlacionadas diretamente com a produtividade por outros autores (Carvalho et al., 2010; Martinez et al., 2007; Severino et al., 2002).

Todos os acessos avaliados apresentaram características semelhantes em relaçáo a seis das 30 características avaliadas, 
segundo a tabela de descritores mínimos para a proteção de cultivares de café, sendo elas: 1) folha: ondulaçáo das bordas (presente) e pubescência na domácia (ausente), 2) fruto: grau de aderência ao ramo (médio), 3) semente: largura (média), cor do endosperma (verde) e tonalidade da película de cobertura (clara). Os resultados relacionados às demais características avaliadas estão apresentados nas tabelas 4 e 5 .

Em relação às variáveis qualitativas das plantas, os mutantes foram reunidos em pequenos grupos, de acordo com as características formato da planta, flexibilidade do ramo ortotrópico, ramo plagiotrópico (posição em relação ao ortotrópico) e intensidade de ramificação plagiotrópica. Pacamara 223 é o único acesso cujas plantas têm copa de formato cônico, diferentemente dos demais acessos e das cultivares comerciais Mundo Novo, Catuaí e Icatu, classificadas por Aguiar et al. (2004) como plantas de formato cilíndrico.

A maioria dos acessos estudados apresentou flexibilidade média do ramo ortotrópico. Cultivares com essa característica são mais adequadas ao uso da colheita mecanizada, uma vez que, nesse tipo de colheita, a alta flexibilidade pode dificultar a retirada do fruto dos ramos e a baixa flexibilidade pode acarretar rachadura ou quebra da haste principal durante a passagem da máquina.

A intensidade da ramificação plagiotrópica do mutante São Bernardo foi caracterizada como baixa, diferenciando-o dos demais acessos, divididos em outros dois grupos, respectivamente com média e alta intensidade de ramificação plagiotrópica. Esse último grupo abriga oito dos 21 acessos avaliados, sendo a característica bastante desejada, uma vez que apresenta alta correlação fenotípica com a produtividade (Carvalho et al., 2010).

Os acessos Semperflorens 238 e Catuaí Erecta também se mostraram dissimilares dos demais em relação aos ramos plagiotrópicos avaliados, por serem eretos em relação ao ortotrópico. Essa característica é interessante quanto se deseja um plantio mais adensado, uma vez que o diâmetro de copa de cultivares com ramificação plagiotrópica ereta será menor. Os dados apresentados na tabela 2 evidenciam o potencial agronômico do germoplasma Catuaí erecta, que apresentou a maior produçáo acumulada (47,03 sacas. $\mathrm{ha}^{-1}$ ) nas duas colheitas realizadas, cerca de $20 \%$ superior à produçáo do acesso Pacamara.

As características avaliadas em relação às flores não se mostraram muito eficientes para diferenciar os acessos, com exceção da quantidade de inflorescência por axila e quantidade de flores por inflorescência, corroborando os dados obtidos por Aguiar et al. (2004) ao caracterizarem cultivares de $C$. arabica por meio dos mesmos descritores mínimos, relacionados às flores. Os acessos Angustifolia e Volutifoliase destacaram-se em relação às duas características, porém ambos apresentaram baixa produtividade, indicando

Tabela 4. Variáveis qualitativas de plantas, flores e frutos avaliadas nos mutantes segundo a tabela de descritores mínimos para a proteção de cultivares de café; formato das plantas (For), haste principal: comprimento do internódio (HP), flexibilidade do ramo ortotrópico (OF), angulação do ramo plagiotrópico (RP), intensidade de ramificação plagiotrópica (IRP), quantidade de inflorescências por axila (IQA), quantidade de flor por inflorescência (FQI), tamanho do fruto (TF), formato do fruto (FF), cor do fruto (CF) e presença de sépalas (PS)

\begin{tabular}{|c|c|c|c|c|c|c|c|c|c|c|c|}
\hline Acessos & For & HP & OF & $\mathbf{R P}$ & IRP & IQA & FQI & TF & FF & CF & PS \\
\hline Pacamara 223 & Côn & $C$ & $M$ & $\mathrm{H}$ & M & $A$ & M & $M$ & 0 & VM & A \\
\hline Polyorthotopica & $\mathrm{CC}$ & $M$ & $M$ & SE & $M$ & M & M & $P$ & $\mathrm{E}$ & VM & A \\
\hline Catuaí Erecta & CC & $M$ & A & $\mathrm{E}$ & M & A & M & $\mathrm{P}$ & 0 & VM & A \\
\hline Goiaba 242 & Cil & $M$ & A & SE & A & $M$ & M & $\mathrm{P}$ & 0 & VA & $P$ \\
\hline Glaucia & CC & $M$ & $M$ & $\mathrm{H}$ & M & A & M & $P$ & 0 & VA & A \\
\hline Pacamara 224 & Cil & $M$ & $M$ & SE & M & $A$ & M & $G$ & 0 & VM & A \\
\hline Laurina 228 & Cil & $C$ & $M$ & SE & A & M & M & MG & 0 & VM & A \\
\hline Polysperma 227 & Cil & $C$ & $M$ & SE & A & $A$ & M & MG & $E$ & VA & A \\
\hline Polysperma 225 & Cil & $C$ & $M$ & $\mathrm{H}$ & A & $M$ & B & MG & $\mathrm{R}$ & VE & A \\
\hline Goiaba 243 & Cil & $C$ & $A$ & SE & A & $M$ & M & $P$ & 0 & VM & $P$ \\
\hline Cera & CC & $C$ & $M$ & $\mathrm{H}$ & A & M & M & $\mathrm{P}$ & 0 & VM & A \\
\hline Semperflorens 1193 & $\mathrm{Cl}$ & $M$ & $M$ & $\mathrm{H}$ & M & B & B & $M$ & 0 & VM & A \\
\hline Semperflorens 238 & CC & $C$ & B & $E$ & M & B & B & MP & $\mathrm{E}$ & VE & A \\
\hline Volutifolia & $\mathrm{CC}$ & $M$ & $M$ & SE & $M$ & A & $A$ & $P$ & 0 & VM & A \\
\hline Angustifolia & $\mathrm{Cl}$ & $C$ & M & $\mathrm{H}$ & M & B & M & MG & 0 & VM & A \\
\hline Laurina 229 & Cil & $C$ & $M$ & $\mathrm{H}$ & M & B & B & $P$ & 0 & VM & A \\
\hline São Bernardo & CC & $C$ & B & $\mathrm{H}$ & B & $M$ & M & $P$ & 0 & VM & A \\
\hline Maragogipe & $\mathrm{Cl}$ & $M$ & $M$ & SE & $M$ & $M$ & M & MG & 0 & VM & A \\
\hline Purpuracens & Cil & $C$ & $A$ & SE & A & A & M & MP & 0 & VE & A \\
\hline Angustifolia & CC & $C$ & $M$ & SE & $M$ & A & $A$ & $P$ & 0 & VM & A \\
\hline Mokka & $\mathrm{CC}$ & $C$ & $A$ & SE & $M$ & B & B & MP & $\mathrm{R}$ & VM & A \\
\hline
\end{tabular}

For: CC - cilíndrico-cônico, Côn - cônico, Cil - cilíndrico, CI - cônico invertido; HP: C - curto, M - médio; OF: A - alta, M - média, B - baixa; RP: H - horizontal, SE - semiereta, E - ereta; IRP, IQA, FQI: A - alta, M - média, B - baixa; TF: MG - muito grande, G - grande, M - médio, P - pequeno, MP - muito pequeno; FF: O - oblongo, $\mathrm{R}$ - redondo, E - elíptico; CF: VM - vermelha média, VE - vermelha escura, VA - vermelha alaranjada; PS: P - presente, A - ausente. 
Tabela 5. Variáveis qualitativas de folhas e sementes dos mutantes, segundo a tabela de descritores mínimos para a proteção de cultivares de café; comprimento da folha (CF), largura da folha (LF), formato da folha (FF), cor da folha na fase jovem (CFJ), cor da folha na fase adulta (CA), intensidade da ondulação das bordas da folha (IOF), profundidade da nervura secundária da folha (PN), presença de domácia na folha (DF), comprimento da semente (CS), espessura da semente (ES) e grau de aderência de película à semente (AS)

\begin{tabular}{|c|c|c|c|c|c|c|c|c|c|c|c|}
\hline Acessos & CF & LF & FF & CFJ & CA & IOF & PN & DF & CS & ES & AS \\
\hline Pacamara 223 & $\mathrm{~L}$ & LAR & LAN & VB & VE & FO & M & $\mathrm{BD}$ & $C$ & $\mathrm{~F}$ & $M$ \\
\hline Polyorthotopica & $C$ & EST & ELI & VB & VE & $M$ & $M$ & PD & $M$ & $M$ & $M$ \\
\hline Catuaí Erecta & M & M & ELI & v & VE & M & $M$ & $\mathrm{BD}$ & $M$ & $M$ & FO \\
\hline Goiaba 242 & M & EST & ELI & $\mathrm{BR}$ & VE & FO & $M$ & $\mathrm{BD}$ & $M$ & $M$ & FO \\
\hline Glaucia & M & EST & ELI & V & VE & M & $M$ & PD & $M$ & $M$ & M \\
\hline Pacamara 224 & $\mathrm{~L}$ & LAR & ELI & V & VE & M & $A$ & $\mathrm{BD}$ & $M$ & $M$ & $\mathrm{FO}$ \\
\hline Laurina 228 & $C$ & EST & ELI & V & VE & FO & M & $\mathrm{BD}$ & $C$ & $\mathrm{~F}$ & FO \\
\hline Polysperma 227 & $C$ & EST & ELI & v & VE & FO & M & $\mathrm{BD}$ & $M$ & $M$ & $M$ \\
\hline Polysperma 225 & M & LAR & ELI & $\mathrm{BR}$ & VE & M & $M$ & $\mathrm{BD}$ & M & $M$ & $M$ \\
\hline Goiaba 243 & $C$ & EST & ELI & $\mathrm{BR}$ & VE & M & M & $\mathrm{BD}$ & M & $M$ & FO \\
\hline Cera & $C$ & EST & ELI & $\mathrm{BR}$ & VE & $\mathrm{FR}$ & $\mathrm{B}$ & $\mathrm{PD}$ & M & $M$ & M \\
\hline Semperflorens 1193 & $C$ & EST & ELI & V & VE & M & $B$ & PD & $M$ & $M$ & FO \\
\hline Semperflorens 238 & $C$ & EST & ELI & V & VE & M & $M$ & PD & $M$ & $M$ & M \\
\hline Volutifolia & $C$ & EST & ELI & v & VE & FO & $A$ & PD & $M$ & M & FO \\
\hline Angustifolia & $C$ & EST & ELI & $\mathrm{BR}$ & VE & M & $\mathrm{B}$ & PD & M & $M$ & FO \\
\hline Laurina 229 & M & M & ELI & V & VE & FO & M & $\mathrm{BD}$ & M & $M$ & M \\
\hline São Bernardo & $C$ & EST & ELI & VB & VE & $\mathrm{FR}$ & $\mathrm{B}$ & $\mathrm{BD}$ & M & $M$ & M \\
\hline Maragogipe & $C$ & EST & ELI & V & VE & $M$ & $M$ & PD & M & $M$ & $M$ \\
\hline Purpuracens & $C$ & EST & ELI & VB & VC & $\mathrm{FR}$ & $\mathrm{B}$ & $\mathrm{BD}$ & $M$ & $M$ & $M$ \\
\hline Angustifolia & M & $M$ & ELI & $\mathrm{BR}$ & VE & $M$ & $M$ & PD & $M$ & $M$ & FO \\
\hline Mokka & $C$ & EST & OV & V & VE & FR & B & $\mathrm{BD}$ & $M$ & $M$ & $M$ \\
\hline
\end{tabular}

FC: C - curto, L - longo, M - médio; LF: EST - estreita, LAR - larga, M - média; FF: ELI - elíptico, OV - ovalado, LAN - lanceolado; CFJ: BR - bronze, V - verde, VB - verde e bronze; CFA: VC - verde-clara, VE - verde-escura; IOF: FR - fraca, M - média, FO - forte; PNF: B - baixa, M - média, A - alta; DF: BD - bem desenvolvida, PD - parcialmente desenvolvida; CS: C - curto, $\mathrm{M}$ - médio; ES: F - fina, $\mathrm{M}$ - média; AS: $\mathrm{M}$ - média, FO - forte.

que, apesar do florescimento abundante, houve baixo vingamento.

Os frutos apresentaram, em geral, formato oblongo, com exceção dos acessos Polysperma 225 e Mokka, descritos como redondos, e dos mutantes Polyorthotopica, Polysperma 227 e Semperflorens 238, descritos como elípticos.

Todos os acessos avaliados apresentaram frutos de coloração vermelha, porém algumas variaçôes de tonalidade foram observadas, como vermelho escuro, vermelho médio e vermelho alaranjado. O controle dessa característica é exercido por apenas um gene, denominado xanthocarpa, com dois alelos, havendo dominância incompleta do alelo $X c$ sobre o $x c$. Dessa forma, os genótipos $X c X c, X c x c$ e $x c x c$ apresentam os fenótipos frutos vermelhos, alaranjados com estrias vermelhas (vermelho claro) e amarelos, respectivamente (Krug e Carvalho, 1940).

Os acessos do mutante Goiaba apresentaram-se dissimilares em relaçáo ao grupo avaliado por apresentarem sépala nos frutos, característica inerente a esse mutante.

$\mathrm{Na}$ tabela 5 estáo apresentados os dados das avaliaçóes de variáveis qualitativas de folhas e sementes dos mutantes segundo a tabela de descritores mínimos para a proteção de cultivares de café, sendo oito características com relação às folhas nas fases jovem e adulta e quatro características com relação às sementes.
Com relação ao comprimento das folhas, houve predominância de mutantes com folhas curtas, sendo que apenas dois acessos do Pacamara diferenciaram-se isoladamente do grupo, apresentando folhas longas. $\mathrm{O}$ acesso Pacamara juntamente com o Polysperma 225 ainda se mostraram dissimilares aos demais acessos em relação à largura das folhas, caracterizadas como largas, enquanto prevaleceram mutantes com folhas estreitas.

Os acessos Pacamara 223 e Mokka apresentaram forma foliar lanceolada e ovalada, respectivamente, diferenciando-se dos demais acessos, que formaram um grupo homogêneo com folhas elípticas.

A cor das folhas na fase jovem foi bastante heterogênea entre os mutantes avaliados, mostrando-se eficiente na diferenciação dos grupos. Sete acessos apresentaram folhas bronze, 11 apresentaram folhas verdes, e sete, verde e bronze. Em relaçáo à cor da folha na fase adulta, apenas o mutante Purpuracens apresentou folha verde-clara, isolando-se do restante do grupo, que apresentou folhas adultas verde-escuras.

Apenas os acessos Pacamara 223 e Laurina 228 apresentaram sementes com comprimento curto e espessura fina, sendo os dos demais mutantes classificados como médios em ambas as características. O grau de aderência da película na semente dividiu os acessos em dois grupos distintos, um deles classificado como forte e outro como médio (Tabela 5). 


\section{CONCLUSÃO}

Existe variabilidade genética entre os acessos avaliados, podendo ser explorados em programas de melhoramento. A tabela de descritores mínimos para a proteção de cultivares de cafés se mostrou eficiente na caracterização e diferenciação dos acessos de mutantes do Banco Ativo de Germoplasma de Cafeeiros do Estado de Minas Gerais, Brasil.

\section{AGRADECIMENTOS}

Os autores agradecem à Fapemig, à Secretaria de Estado de Ciência e Tecnologia (Sect/MG), ao Consórcio de Pesquisa Café e ao Instituto Nacional de Ciência e Tecnologia do Café (INCT Café/CNPq), pelo apoio financeiro ao projeto, e ao CNPq, pela concessão da bolsa PNPD (JCR).

\section{REFERENCIAS}

AGUIAR, A.T.E.; GUERREIRO-FILHO, O.; MALUF, M.P.; GALLO, P.B.; FAZUOLI, L.C. Caracterização de cultivares de Coffea arabica mediante utilização de descritores mínimos. Bragantia, v.63, p.179192, 2004. http://dx.doi.org/10.1590/S0006-87052004000200003

BOTELHO, C.E.; MENDES, A.N.G.; CARVALHO, G.R.; BARTHOLO, G.F.; CARVALHO, S.P. Seleção de progênies $\mathrm{F}^{4}$ de cafeeiros obtidas pelo cruzamento de Icatu com Catimor. Revista Ceres, v.57, p.274-281, 2010a. http://dx.doi.org/10.1590/S0034-737X2010000300010

BOTELHO, C.E.; REZENDE, J.C.; CARVALHO, G.R.; CARVALHO, A.M.; ANDRADE, V.T.; BARBOSA, C.R. Adaptabilidade e estabilidade fenotípica de cultivares de café arábica em Minas Gerais. Pesquisa Agropecuária Brasileira, v.45, p.1404-1411, 2010b. http://dx.doi. org/10.1590/S0100-204X2010001200010

BRASIL. Ministério da Agricultura, Pecuária e Abastecimento. Serviço Nacional de Proteção de Cultivares. Instruçóes para execução dos ensaios de distinguibilidade, homogeneidade e estabilidade de cultivares de café (Coffea spp). Diário Oficial da Uniāo, Poder Executivo, Brasília, DF, 21 nov. 2000. Seção 1, p. 6-7. Disponível em: <http://www.agricultura. gov.br/arq_editor/file/vegetal/RegistroAutorizacoes/Formularios\%20 Prote $\%$ C3\%A7\%C3\%A3o\%20Cultivares/CAFE_US.doc>. Acesso em: 9 out. 2014 .

CAMPOS, A.; ZACARIAS, A.; COSTA, D.; NEVES, L.; BARELLI, M.; SOBRINHO, S.; LUZ, P. Avaliaçáo de acessos de mandioca do banco de germoplasma da UNEMAT Cáceres - Mato Grosso. Revista Trópica: Ciências Agrárias e Biológicas, v.4, p.44-54, 2010. Disponível em: <http://www.periodicoseletronicos.ufma.br/index. $\mathrm{php/ccaatropica/article/view/156>.}$

CARVALHO, A. Causas da baixa produtividade de C. arabica L. var. maragogipe Hortex Froener. Campinas: Instituto Agronômico, 1939. 45p. (Boletim Técnico, 59)

CARVALHO, A.; MÔNACO, L.C.; FAZUOLI, L.C. Melhoramento do cafeeiro, XL Estudos de híbridos de café Catuai. Bragantia, v.38, p.202216, 1979. http://dx.doi.org/10.1590/S0006-87051979000100022

CARVALHO, A.; MEDINA FILHO, H.P.; FAZUOLI, L.C.; GUERREIRO FILHO, O.; LIMA, M.M. Aspectos genéticos do cafeeiro. Revista Brasileira de Genética, v.14, p.135-183, 1991.
CARVALHO, A.M.; MENDES, A.N.G.; CARVALHO, G.R.; BOTELHO, C.E; GONÇALVES, F.M.A.; FERREIRA, A.D. Correlação entre crescimento e produtividade de cultivares de café em diferentes regióes de Minas Gerais, Brasil. Pesquisa Agropecuária Brasileira, v.45, p.269-275, 2010. Disponível em: <http://www.scielo. br/pdf/pab/v45n3/v45n3a06.pdf>.

COIMBRA, R.R.; MIRANDA, G.V.; CRUZ, C.D.; SILVA, D.J.H.; VILELA, R.A. Amostragem de acessos introduzidos e melhorados para composição de uma coleção núcleo de milho, Revista Ciência Agronômica, v.43, p.184-194, 2012. http://dx.doi.org/10.1590/ S1806-66902012000100023

COSTA, T.S.; SILVA, A.V.C., LEDO, A.S.; SANTOS, A.R.V.; SILVA JUNIOR, J.F. Diversidade genética de acessos do banco de germoplasma de mangaba em Sergipe. Pesquisa Agropecuária Brasileira, v.46, p.499-508, 2011. Disponível em: <http://www.scielo.br/pdf/ pab/v46n5/07.pdf>.

FERRÃO, R.G.; CRUZ, C.D.; FERREIRA, A.; CECON, P.R.; FERRÃO, M.A.G.; FONSECA, A.F.A.; CARNEIRO, P.C.S.; SILVA, M. Parâmetros genéticos em café Conilon. Pesquisa Agropecuária Brasileira, v.43, p.61-69, 2008. http://dx.doi.org/10.1590/S0100204X2008000100009

FERREIRA, D.F. SISVAR: um programa para análises e ensino de estatística. Revista Symposium, v.6, p.36-41, 2008.

GUEDES, J.M.; VILELA, D.J.M.; REZENDE, J.C.; SILVA, F.L.; BOTELHO, C.E.; CARVALHO, S.P. Divergência genética entre cafeeiros do germoplasma Maragogipe. Bragantia, v.72, p.127-132, 2013. http://dx.doi.org/10.1590/S0006-87052013000200003

KRUG, C.A.; CARVALHO, A. Genética de Coffea. III-Hereditariedade da cor amarela dos frutos. Campinas: Instituto Agronômico, 1940. 16p. (Boletim Técnico, 82)

LIMA, M.S.; CARNEIRO, J.E.S.; CARNEIRO, P.C.S.; PEREIRA, C.S.; VIEIRA, R.F.; CECON, P.R. Caracterização da variabilidade genética entre genótipos de feijoeiro comum por meio de descritores morfoagronômicos. Crop Breeding and Applied Biotechnology, v.12, p.76-84, 2012. http://dx.doi.org/10.1590/S1984-70332012000100010

MARTINEZ, H.E.P.; AUGUSTO, H.S.; CRUZ, C.D.; PEDROSA, A.W.; SAMPAIO, N.F. Crescimento vegetativo de cultivares de café (Coffea arabica L.) e sua correlaçáo com a produçáo em espaçamentos adensados. Acta Scientiarum Agronomy, v.29, p.481-489, 2007. http://dx.doi.org/10.4025/actasciagron.v29i4.404

MARTINS, A.L.M.; PEROSO, P.A.C.; FAZUOLI, L.C.; GONÇALVES, W. Avaliação de progênies de cafés 'Catuaí Amarelo' e 'Catuaí Vermelho' na região de Pindorama (SP). Bragantia, v.51, p.31-38, 1992. http://dx.doi.org/10.1590/S0006-87051992000100005

MÔNACO, L.C. Melhoramento do cafeeiro. XVII - Seleção do café Maragogipe A. D. Bragantia, v.19, p.459-492, 1960. http://dx.doi. org/10.1590/S0006-87051960000100029

MÔNACO, L.C.; CARVALHO, A. Melhoramento do cafeeiro. XXIII - Novos dados sobre a variabilidade em linhas isogênicas de café. Bragantia, v.23, p.13-22, 1964. http://dx.doi.org/10.1590/ S0006-87051964000100002

SEVERINO, L.S.; SAKIYAMA, N.S.; PEREIRA, A.A.; MIRANDA, G.V.; ZAMBOLIM, L.; BARROS, U.V. Associações da produtividade com outras características agronômicas de café (Coffea arabica L. “Catimor"), Acta Scientiarum Agronomy, v.24, p.1467-1471, 2002.

SCOTT, A.J.; KNOTT, M.A. Cluster analysis method for grouping means in the analysis of variance. Biometrics, v.30, p.507-512, 1974. Disponível em: <http://www.ime.usp.br/ abe/lista/pdfXz71qDkDx1.pdf>. 